\title{
Surgical retrieval of entrapped coronary guidewire remnant - 3-year angiographic evaluation
}

\author{
Wojciech Domaradzki ${ }^{1,2}, K_{\text {Kzysztof Sanetra }}^{1,2}$, Bartosz Skwarna ${ }^{3}$, Justyna Jankowska-Sanetra ${ }^{3}$, \\ Marek Cisowski ${ }^{1,2}$ \\ ${ }_{1}^{1} 1^{\text {st }}$ Department of Cardiac Surgery, American Heart of Poland, Bielsko-Biala, Poland \\ ${ }^{2}$ Center for Cardiovascular Research and Development, American Heart of Poland, Bielsko-Biala, Poland \\ ${ }^{3} 2^{\text {nd }}$ Department of Cardiology, American Heart of Poland, Bielsko-Biala, Poland
}

Kardiochirurgia i Torakochirugia Polska 2018; 15 (4): 258-261

Percutaneous interventions, despite constant improvement of hardware and techniques, are not free of complications. Although problems with delivery systems occur rarely, knowledge how to manage them is an obligatory component of an interventional cardiologist's training and practice.

Breakage of the intravascular equipment is estimated to occur in $0.1-0.2 \%$ of all procedures $[1,2]$. If such complications occur, there are three possible options: percutaneous removal (when possible), a surgical procedure (removal/removal with coronary artery bypass grafting/sole coronary artery bypass grafting) or leaving the fragment intact inside the vessel.

There are numerous cases described in the literature. However, it is difficult to find two similar clinical descriptions and therapeutic algorithms. In consequence, there are no clear procedural guidelines. It is also uncommon to obtain long-term follow-up in those patients.

Although percutaneous removal seems to be the most desired treatment, it is always dependent on the operator's experience, as the risk of vascular trauma, coronary spasms or new fragmentation must be taken into consideration. Since the material in separate cardiology departments is not extensive enough for a decisive study, the knowledge must be built upon a series of case reports. It would be perfect for the clinician to review the literature with long-term follow-up as well, especially in controversial cases.

The presented letter to the editor contains a long-term follow-up to a case reported previously [3]. The patient is a 67-year-old male patient with unstable angina, who underwent an unsuccessful angioplasty procedure over three years ago, which was followed by surgical removal of a broken guidewire and coronary artery bypass grafting. In this case, coronarography findings were quite interesting.

The patient's history includes several cardiovascular incidents and interventions. At the age of 55, he was referred to the invasive cardiology department with unstable angina. He underwent angioplasty of the anterior inter- ventricular branch of the left coronary artery (left anterior descending - LAD) with implantation of a bare metal stent (BMS). Due to the recurrence of the symptoms related to restenosis, repeat $L A D$ angioplasty was performed at the age of 62 - this time with the use of drug-eluting stent. This time the angiography revealed significant stenosis in the right coronary artery (RCA) and circumflex artery (Cx), so the staged percutaneous treatment was planned.

At the age of 63 the drug-eluting stent was implanted in the right coronary artery. The last part of the staged endovascular procedure was planned for the following month. A guiding catheter (EBU 3.5, $6 \mathrm{Fr}$ ) was introduced through femoral access to initiate the procedure of circumflex artery stenting. A drug-eluting stent was implanted in the medial segment of the $C x$ at a pressure of 16 atm, covering the outlet of the second obtuse marginal artery (OM2). There was no significant stenosis in the outlet of the $\mathrm{OM} 2$ and full dilatation of the stented vessel was achieved. The angioplasty was 12 min long and the duration of the fluoroscopy was about $3 \mathrm{~min}$. The dose of radiation was $548 \mathrm{mGy}$. At the end of the procedure the guidewire became entrapped on the stent structure. The percutaneous manipulations using a balloon were unsuccessful. Finally, the stent became deformed and the distal segment of the guidewire was detached (Figs. 1 A, B). The attempt to deploy another balloon through the deformed stent structure failed. The time of the procedure exceeded $120 \mathrm{~min}$ and the duration of the fluoroscopy was $41 \mathrm{~min}$. The patient received a dose of $6695 \mathrm{mGy}$. Type 4a myocardial infarction was diagnosed because of elevation of troponin and CK-MB levels. The patient's condition was stable and there was no deterioration in left ventricular ejection fraction.

The patient was referred to the cardiac surgery department. He underwent a procedure with the use of extracorporeal circulation. After opening the aorta, the guidewire fragment was visible in the ostium of the left main coronary artery (LM). It was removed under direct vision along with the attached stent by gentle traction towards the

Address for correspondence: Krzysztof Sanetra MD, $1^{\text {st }}$ Department of Cardiac Surgery, American Heart of Poland, 101 Armii Krajowej St, 43-316 Bielsko-Biala, Poland, phone: +48 692030 003, e-mail: krzyssan@poczta.onet.pl

Received: 30.08.2018, accepted: 29.09.2018. 


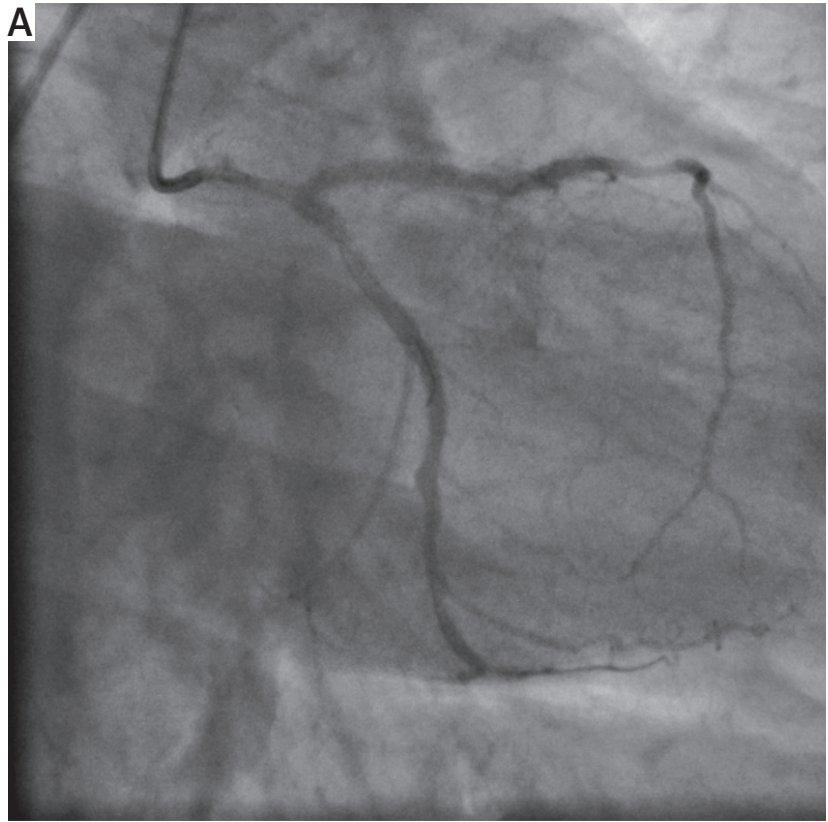

Fig. 1. A, B - The entrapped guidewire

aortic lumen (Fig. 2). Coronary artery bypass grafting was performed (Ao-Cx) using the patient's saphenous vein. The time of extracorporeal circulation was $35 \mathrm{~min}$ and the aortic cross-clamp time was $24 \mathrm{~min}$. The time of hospitalization was uneventful and the patient was discharged directly to the rehabilitation department 6 days after the surgery.

The following 3 years were uneventful. The patient experienced no chest pain or dyspnea. The first symptoms appeared early in the morning. The patient presented with typical chest pain and ST segment elevation over the anterior wall. The biomarkers of cardiac necrosis were not elevated. He was referred to the invasive cardiology department immediately. The performed coronarography revealed distal stenosis in the left main coronary artery (LM - 20\%); proximal restenosis (90\%) and medial $40-50 \%$ stenosis in the LAD; stenosis in the medial segment of $C x$ with patent bypass graft distally and patent RCA with no restenosis (Figs. $3 \mathrm{~A}-\mathrm{C}, 4 \mathrm{~A}, \mathrm{~B}$ ). The 3-4 $\mathrm{mm}$ long remnant of the entrapped guidewire was visible contiguously to the $\mathrm{Cx}$ lumen, probably entrapped within the atherosclerotic plaque. Interestingly, the comparison to previous coronarography (3-year interval) did not show any progress in reduction of the vessel lumen in this segment. A procedure of LAD stenting was performed in a standard manner. A $3.5 \times 12 \mathrm{~mm}$ drug-eluting stent was implanted in the proximal LAD under the pressure of $16 \mathrm{~atm}$ (Fig. 5). Immediate relief of symptoms was observed. The hospitalization was uneventful, and the patient was discharged home 2 days after the procedure.

The problem of entrapped hardware elements may be underestimated, as probably just a small proportion of cases is reported.

The decision whether to remove the foreign body from the vessel is usually disputable. It is made on the basis of the patient's condition, location and size of the remnant. It
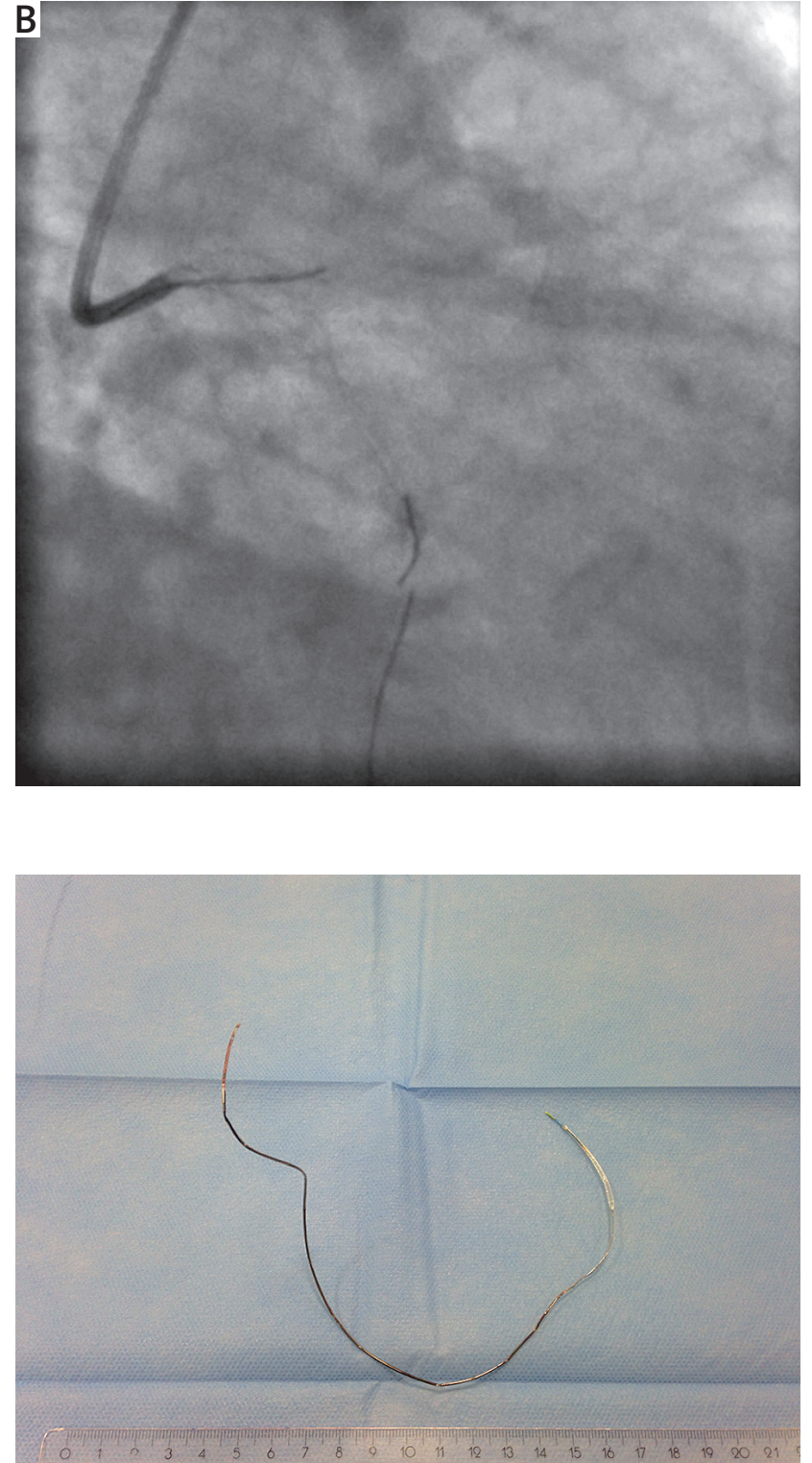

Fig. 2. The removed guidewire fragment

is also important to take the risk of infection, perforation, arrhythmia, and progressive thrombosis into consideration. The situation is easier in the case of large remnants located within the ascending aorta - they should be removed due to the high risk of cerebral vascular embolization [4].

If entrapped hardware fragments are small and located in relatively small vessels, the situation is not that clear anymore. Several maneuvers can be made to remove them percutaneously. It is very important to adjust the traction in order not to cause serious damage. Should the attempt to remove the foreign body from the vessel fail, there are still two options remaining. The remnant may be either left in situ or the patient can be referred to a cardiothoracic surgeon for urgent surgery.

Hartzler et al. analyzed a series of cases and reported 5 patients with hardware retained in the coronary arteries, who experienced no adverse sequelae [2]. However, it is 

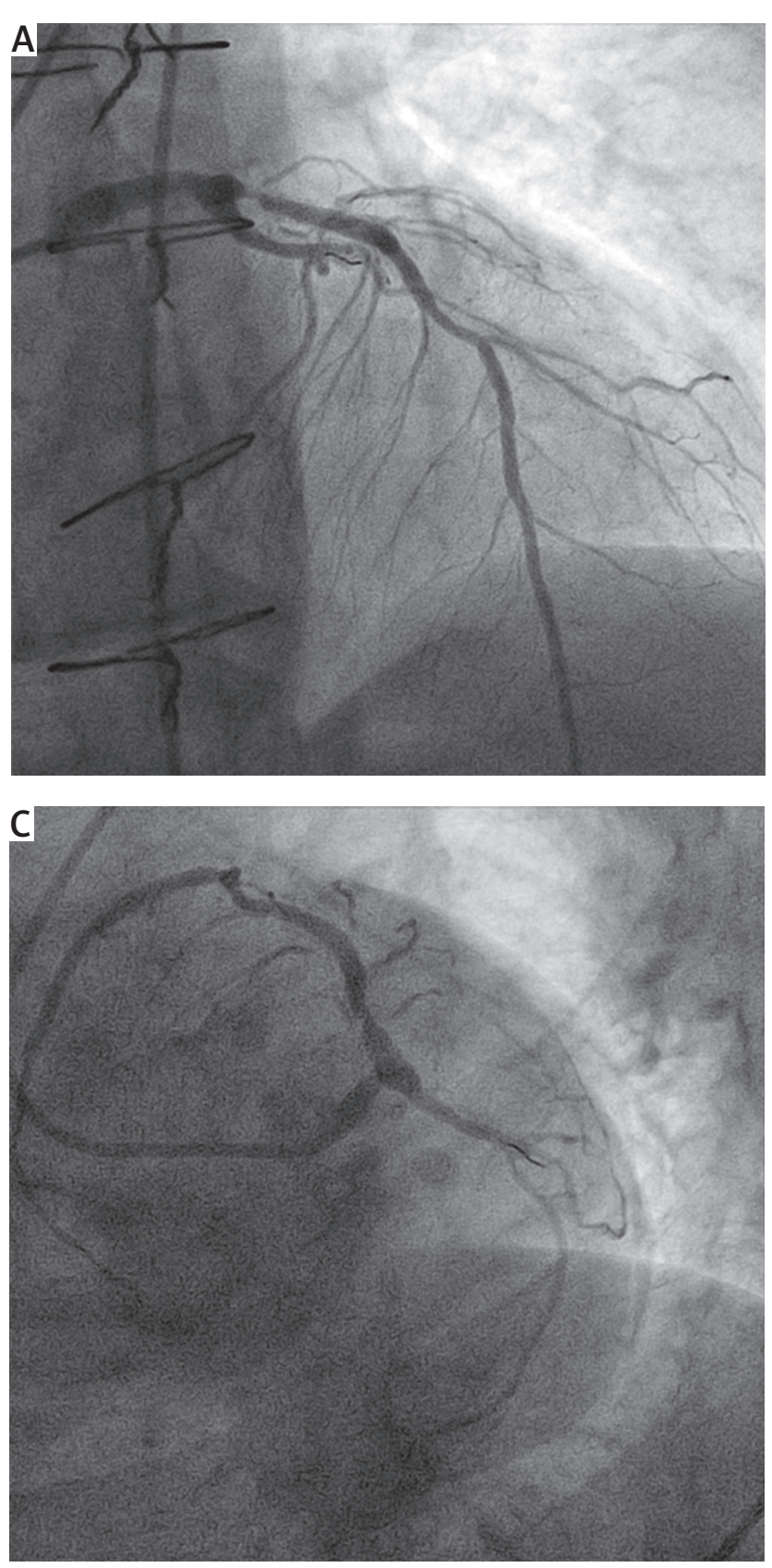

important to note that in 3 of those patients the treated vessels were chronically occluded. The remaining 2 patients had a long-term follow-up, but only one of them had coronarography within 2 years after the entrapment. Furthermore, the retained element in this patient was a gold band. The other patient received only clinical evaluation.

It may seem that small hardware elements, entrapped within the coronary artery, may not be complicated, particularly when they are retained with the total coronary occlusions or within a distal part of the vessel. There is a hypothesis that the hardware fragment becomes covered with endothelium, rendering it immobile and non-thrombogenic [2]. Successful cases of using stents to fix the remnant to the vessel wall and therefore prevent embolization and occlusion are also described $[5,6]$.

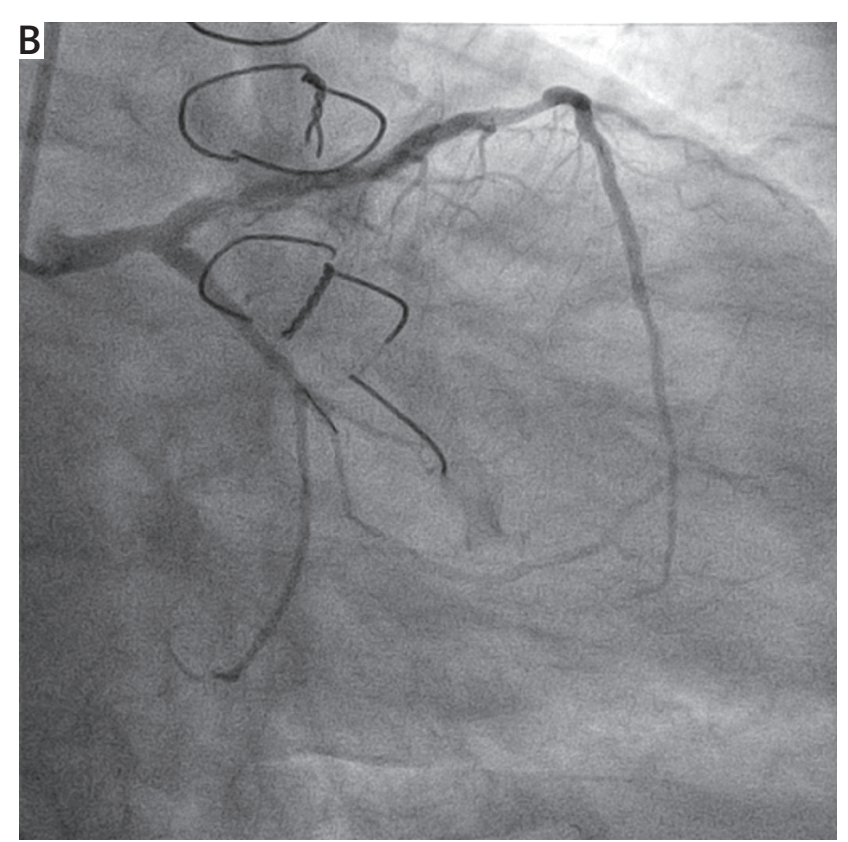

Fig. 3 A-C. Three-year follow-up coronarography

In contrast, Doorey and Stillabower report a case of artery stenosis proximally from a retained hardware element in 3-month control angiography, despite oral anticoagulation [7].

Al-Moghairi and Al-Amri analyzed 48 reports of 67 patients [8]. They have found that the wire entrapment was reported in the RCA in 22 cases, the LAD in 25 cases, the left circumflex artery (LCX) in 19 cases and the ramus intermedius artery (IM) in 2 cases. The percutaneous techniques used for retrieval of entrapped guidewire fragments include stenting against the vessel wall (7 cases), snare loop (9 cases), double or triple wire technique (3 cases), bioptome (1 case), Tornus microcatheter (1 case), deep-guide catheter wedging with balloon inflation (6 cases) and pigtail catheter (1 case). 

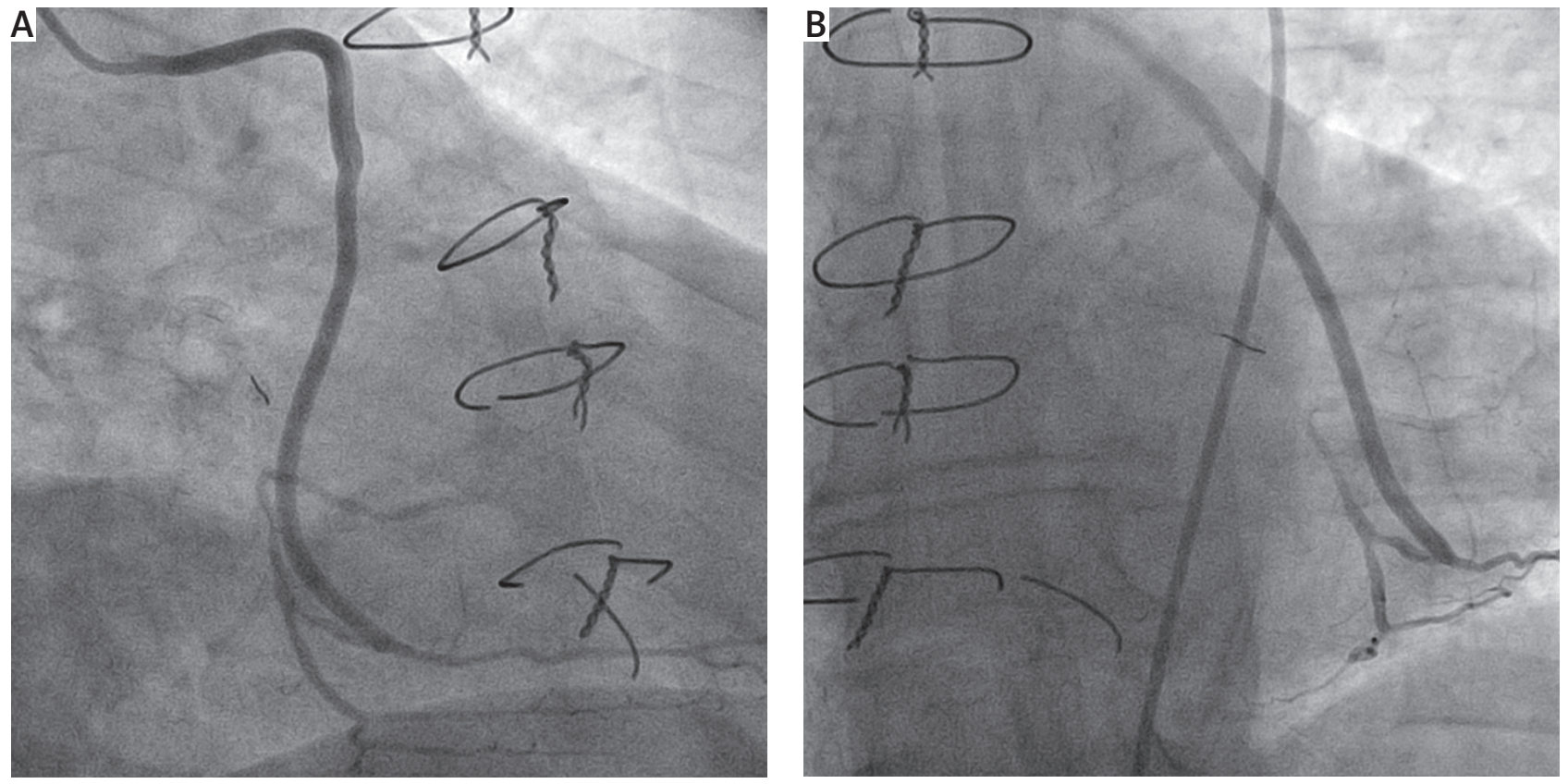

Fig. 4. A, B. Patent Ao-Cx graft

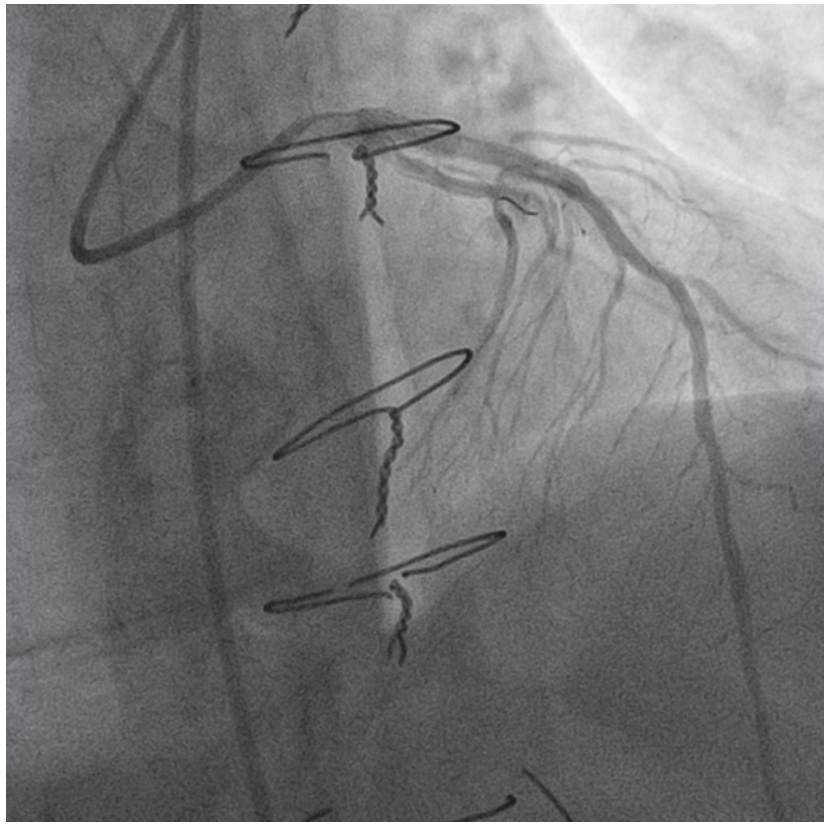

Fig. 5. Control coronarography after drug-eluting stent implantation

Surgery, although risky, was performed in several cases $[4,6,7]$. The approach includes both coronary arteriotomy and aortotomy. Most authors decide to perform coronary artery bypass grafting as well. It is quite justified, as both arteriotomy and aortotomy practically do not allow one to properly decide whether the endothelium of the vessel is damaged, which can trigger adverse incidents within the artery, including total occlusion.

We suspect that in the present case, the fixation of the remnant within the plaque resulted in the small free margin being covered with endothelium or atherosclerotic material. The result was loss of thrombogenicity of the guidewire. The remnant triggered no incidents within the vessel, despite lack of anticoagulation. However, if the guidewire had detached in a different part and, in consequence, remained in the artery lumen, complications might have been expected. Both cardiologists and cardiothoracic surgeons should be aware of the potential problem and perform follow-up coronarography after a retrieval procedure, as sometimes small remnants may be left incidentally and additional anticoagulation may be indicated.

\section{Disclosure}

The authors report no conflict of interest.

\section{References}

1. van den Brand $M$, de Feyter P, Serruys P, Zijlstra F, Bos E. Fracture of a balloon on a wire device during coronary angioplasty. Cathet Cardiovasc Diagn 1989; 16: 253-257.

2. Hartzler GO, Rutherford BD, McConahay DR. Retained percutaneous transluminal coronary angioplasty equipment components and their management. Am J Cardiol 1987; 60: 1260-1264

3. Domaradzki W, Sanetra K, Skwarna B, Król M, Kuczera M, Cisowski M. Surgical removal of entrapped guidewire fragment following direct circumflex artery angioplasty and stenting. Kardiochir Torakochirur Pol 2015; 12: 242-245.

4. Alexiou K, Kappert U, Knaut M, Matschke K, Tugtekin SM. Entrapped coronary catheter remnants and stents: must they be surgically removed? Tex Heart Inst J 2006; 33: 139-142.

5. Chu CY, Lin TH, Su HM, Voon WC, Lai WT, Sheu SH. Management of a retained coronary guidewire fragment during percutaneous transluminal coronary angioplasty: a case report. Kaohsiung J Med Sci 2009; 25: 151-155.

6. Lopez-Minguez JR, Davila E, Doblado M, Merchán A, González R, Alonso F. Rupture and intracoronary entrapment of an angioplasty guidewire with the X-Sizer thromboatherectomy catheter during rescue angioplasty. Rev Esp Cardiol 2004; 57: 180-183.

7. Doorey AJ, Stillabower M. Fractured and retained guide-wire fragment during coronary angioplasty-unforeseen late sequelae. Cathet Cardiovasc Diagn 1990; 20: 238-240.

8. Al-Moghairi AM, Al-Amri HS. Management of retained intervention guidewire: a literature review. Curr Cardiol Rev 2013; 9: 260-266. 